\title{
BMJ Open Comparing organ donation decisions for next-of-kin versus the self: results of a national survey
}

Christopher Weiyang Liu (10, ${ }^{1,2,3}$ Lynn N Chen, ${ }^{4}$ Amalina Anwar, ${ }^{5}$ Boyu Lu Zhao, ${ }^{5}$ Clin K Y Lai, ${ }^{5}$ Wei Heng Ng, ${ }^{5}$ Thangavelautham Suhitharan, ${ }^{2,3,6}$ Vui Kian Ho, ${ }^{2,3,6}$ Jean C J Liu (1) ${ }^{5,7}$

To cite: Liu CW, Chen LN, Anwar A, et al. Comparing organ donation decisions for next-of-kin versus the self: results of a national survey. BMJ Open 2021;11:e051273. doi:10.1136/ bmjopen-2021-051273

- Prepublication history and additional supplemental material for this paper are available online. To view these files, please visit the journal online (http://dx.doi.org/10.1136/ bmjopen-2021-051273).

CWL and LNC are joint first authors.

Received 14 March 2021 Accepted 19 October 2021
Check for updates

(C) Author(s) (or their employer(s)) 2021. Re-use permitted under CC BY-NC. No commercial re-use. See rights and permissions. Published by BMJ.

For numbered affiliations see end of article.

Correspondence to

Dr Jean C J Liu;

jeanliu@yale-nus.edu.sg

\section{ABSTRACT}

Objectives Intensive care audits point to family refusal as a major barrier to organ donation. In this study, we sought to understand refusal by accounting for the decisionmaker's mindset. This focused on: (1) how decisions compare when made on behalf of a relative (vs the self); and (2) confidence in decisions made for family members.

Design Cross-sectional survey in Singapore.

Setting Participants were recruited from community settings via door-to-door sampling and community eateries.

Participants 973 adults who qualified as organ donors in Singapore.

Results Although $68.1 \%$ of participants were willing to donate their own organs, only $51.8 \%$ were willing to donate a relative's organs. Using machine learning, we found that consistency was predicted by: (1) religion, and (2) fears about organ donation. Conversely, participants who were willing to donate their own organs but not their relative's were less driven by these factors, and may instead have resorted to heuristics in decision-making. Finally, we observed how individuals were overconfident in their decision-making abilities: although $78 \%$ had never discussed organ donation with their relatives, the large majority expressed high confidence that they would respect their relatives' wishes on death.

Conclusions These findings underscore the distinct psychological processes involved when donation decisions are made for family members. Amidst a global shortage of organ donors, addressing the decision-maker's mindset (eg, overconfidence, the use of heuristics) may be key to actualizing potential donors identified in intensive care units.

\section{INTRODUCTION}

Solid organ transplantation is widely recognised as a life-saving treatment for end-stage organ failure. ${ }^{1}$ Each year, nearly 150000 organs are transplanted worldwide, improving patient outcomes and the quality of life. ${ }^{2}$ Nonetheless, the number of transplant surgeries performed each year caters to a mere $10 \%$ of the demand, with numbers constrained by a global shortage of donor organs. $^{2}$

\section{STRENGTHS AND LIMITATIONS OF THIS STUDY}

$\Rightarrow$ We used a multidisciplinary approach combining psychology theory and machine learning analyses to understand family refusal in a novel manner.

$\Rightarrow$ We directly compared organ donation decisions made from the self versus for next-of-kin, and also documented overconfidence in the decision-making process.

$\Rightarrow$ The study was conducted in an urban setting and may not apply to rural contexts.

$\Rightarrow$ Because we relied on self-reported measures, the findings may be influenced by recall biases and may not generalize to real-life decisions.

To address the shortage, there have been concerted efforts to increase the rate of deceased organ donation worldwide. ${ }^{3} 4$ In terms of bottlenecks, audits of intensive care units implicate family refusal as a major barrier to donation. ${ }^{56}$ Often, when a deceased patient is identified as a potential donor, family members are consulted prior to organ retrieval. In an average of two in five of these cases, however, the family refuses to donate the patient's organs. ${ }^{57}$

\section{Accounting for family refusal}

A large body of research has sought to account for family refusal by reviewing medical records or interviewing next-of-kin. ${ }^{7-10}$ One crucial predictor is whether relatives are aware of the deceased's wishes: in general, next-of-kin enact a patient's choice if they are aware of it. $^{711}$ However, an estimated $50 \%$ of families do not know the deceased's preferences, and are influenced instead by factors ranging from the context of the request (eg, timing, background of the requestor), to pre-existing characteristics of the decision-maker (eg, demographics, beliefs about death, views on organ donation). ${ }^{7-9} 1213$ By and large, these factors overlap greatly with those predicting donation choices for the self. ${ }^{91415}$ 
Although this overlap may suggest similarity in the self- versus family decision-making process, it cannot explain the well-documented discrepancy between: (1) high public endorsement of organ donation (for the self) versus (2) low rates of family acceptance (when deciding for next-of-kin). ${ }^{16}{ }^{17}$ Likewise, when participants are surveyed, they report being more willing to donate their organs than a relative's organs ${ }^{18}{ }^{19}$ —a stark drop-off not observed for other death-related procedures (eg, autopsy). ${ }^{18}$ Together, these systematic shifts suggest that the psychology of decision-making may differ when it comes to next-of-kin. This is a piece of the organ donation puzzle that we know little about, but may be central to actualizing potential donors identified in intensive care units.

\section{Decision-making for the self versus for others}

Outside the field of organ donation, social scientists have described how choices change when they are made on behalf of others. ${ }^{20}$ For example, risks may be assessed differently because third-party decision-makers are detached, perceive the situation differently, or-conversely-feel a greater weight of responsibility for the outcomes (leading to more conservative choices).$^{20}$ Pertaining to medical decision-making, however, these general tendencies fall short of ethical guidelines prescribing how decisions should be made for incapacitated patients. ${ }^{21}$

As a case in point, ethicists typically argue for 'substituted judgement': if a patient's wishes have not been documented, a surrogate family member should strive to make the same decision that the patient would have made for himself or herself. ${ }^{21}$ However, extant research suggests that this rarely occurs. When decision-makers are shown hypothetical end-of-life scenarios and asked to predict their family member's treatment preferences, they typically make inaccurate judgments. ${ }^{22}$ Nonetheless, both surrogates and patients report high confidence that the surrogate will carry out the patient's wishes-a level of overconfidence that impedes advance care planning and conversations about end-of-life wishes. ${ }^{23}$ This overconfidence, in turn, results in high levels of surrogate stress at the point of decision-making. ${ }^{2425}$

\section{The current study}

Although surrogate decision-making has been described for end-of-life patient care, analogous research has not been conducted for organ donation. To address this gap, we used data from a large cross-sectional survey to understand the distinct mind-set of decision-makers as they contemplate organ donation for a relative.

First, we hypothesized that there would be a greater willingness to donate one's own organs than a family member's organs. Correspondingly, we sought to identify factors predicting the shift from being a willing organ donor (for the self) to refusing organ donation (for a family member). This strategy stands in contrast to the typical analysis in organ donation studies, which have focused on predicting decisions for the self or the family member independently (rather than the discrepancy between these). ${ }^{10}$

Second, drawing from research on surrogate decisions for incapacitated patients, ${ }^{162}{ }^{26}$ we investigated the role of overconfidence in family refusal. Specifically, we hypothesized that overconfidence would similarly characterize the mindset of individuals making organ donation decisions on behalf of another.

\section{METHOD}

\section{Study design and population}

Our study was conducted in Singapore, a city state in Asia with a low rate of deceased organ donations (4.41 per million population in 2019). ${ }^{27}$ An opt-out system is in place for donation of the kidney, liver, heart and cornea (implemented via the country's Human Organ Transplant Act), ${ }^{28}$ while an opt-in system applies to donation of all other organs and tissues (eg, skin, bone) and for individuals who do not qualify for presumed consent. ${ }^{29}$ Under the opt-in context, family members can voluntarily donate relatives' organs if no prior decision has been registered. ${ }^{29}$ In the opt-out context, although next-of-kin cannot legally over-ride the presumed consent once brain death has been certified, they are often consulted to identify a patient's expressed or implied wishes prior to the impending brain or circulatory death. This may lead to withdrawal of cardiopulmonary support in light of medical futility, prior to brain death assessment. ${ }^{30}$

From September 2016 to March 2019, we surveyed 973 adults who qualified as organ donors under Singapore's Human Organ Transplant Act. ${ }^{28}$ As the inclusion criteria, participants were: (1) citizens or permanent residents of Singapore and (2) who were aged $\geq 21$ years old. In line with the Act, participants were excluded if they were mentally incapacitated.

\section{Survey administration}

To obtain a representative sample, participants were recruited both door-to-door and via community eateries. For door-to-door recruitment, households were identified using cluster-sampling (by selecting districts in Singapore) followed by simple random sampling (by selecting postal codes within each district). For each postal code, trained interviewers then knocked on doors systematically during weekday evenings and weekends, selecting as respondent the member of the household whose birthday was most recent. (Details of this methodology have been published elsewhere. ${ }^{14}$ For recruitment via community eateries, we visited two popular food halls during the weekday lunch period (12:00-16:00). Trained interviewers then systematically approached each occupied table and invited diners to participate.

As part of a larger study, data collection took place in three waves (Wave 1: September 2016-July 2017, Wave 2: May 2017-July 2017 and Wave 3: July 2018-March 2019), and responses were merged to form a single database. Online supplemental appendix 1 gives a detailed 
breakdown of each collection phase and how survey versions differed. (As the key results did not change as a function of wave, subsequent analyses collapsed across this factor.)

\section{Main outcome measures}

Following guidelines on survey construction in healthcare, ${ }^{31}$ questionnaire items were developed using prior measures in both the organ donation and medical surrogacy literature. ${ }^{1823}$ The primary outcome variables were: (1) deciding on organ donation for the self (whether participants would like to donate their organs on death), and (2) deciding on organ donation for a family member (whether participants would like to donate a family member's organs on death).

To examine overconfidence, a subset of participants (from Wave 2) rated how confident they were that-on their family member's death-they would respect his/ her wishes regarding organ donation (rated using 5-point scales anchored on one end with $1=$ 'Not confident at all' and $5=$ 'Absolutely confident'). These were compared with participants' self-reports of: (1) whether the family member had ever discussed his/her wishes concerning organ donation, and (2) the extent to which participants thought they were aware of their family member's wishes (rated on a 5-point scale with $1=$ 'Absolutely unaware' and $5=$ 'Absolutely aware', with ratings of 4 or five representing awareness). For comparison, an analogous set of questions were asked regarding decisions family members may make for the participant (in Waves 1 and 2).

\section{Predictor variables}

As predictors, we collected a range of demographic variables commonly used to account for individual or family decision-making: gender, age, self-identified race/ ethnicity, religion, marital status, education, house type, and household size.

Additionally, participants in Wave 1 and 2 rated the extent to which each of 18 statements characterised their organ donation concerns for a family member. These questions, drawn from previous studies on the topic, ${ }^{18}$ asked participants about their discomfort pertaining to: (1) mortality ( 1 item: 'I am uncomfortable thinking about my family member's death in general'); (2) clinical management (five items: for example, 'I am afraid that my family member may not get optimal medical care; that the doctors may prematurely declare him/her dead just to have his/her organs donated); (3) donation suitability and equitability (4 items: for example, 'I am concerned that my family member's organ donation may end up benefitting rich people more than the average person'); (4) post-death procedures (3 items: for example, 'I am uncomfortable with someone cutting up my family member's dead body); (4) honoring the deceased ( 1 item: 'I find organ donation disrespectful to a deceased family members'); (6) spirituality (3 items: for example, 'I am afraid that my family member's reincarnation may be influenced by organ donation'); and (7) family dynamics ( 1 item: 'I am afraid that other family members may not agree with my decision') ${ }^{18}$ Each item was rated using a 5-point scale anchored on one end with $1=$ 'Strongly disagree' and $5=$ ='Strongly agree', and scores were averaged to form a scale (Organ Donation Fears: Family; Cronbach's $\alpha=0.94)$. Similarly, participants rated a corresponding set of concerns for themselves (Organ Donation Fears: Self; Cronbach's $\alpha=0.93$ ).

As decisions about family members may be shaped by culture, participants in Wave 1 completed the Cultural Orientation Scale, indicating whether they viewed themselves 'collectively' - as part of social groups such as families—or 'individualistically', independent of groups. ${ }^{32}$ Using 5-point scales (1='Strongly disagree' and $5=$ 'Strongly agree'), participants rated: 4 items on hierarchical relationships within a collective (Vertical Collectivism, for example, 'It is my duty to take care of my family, even when I have to sacrifice what I want'; Cronbach's $\alpha=0.80$ ), 4 items on equal relationships within the collective (Horizontal Collectivism, for example, 'To me, pleasure is spending time with others'; Cronbach's $\alpha=0.78$ ), 4 items on hierarchical relationships among individuals (Vertical Individualism, for example, 'Winning is everything'; Cronbach's $\alpha=0.74$ ) and four items on equalstanding relationships among individuals (Horizontal Individualism, for example, 'I'd rather depend on myself that others'; Cronbach's $\alpha=0.76$ ). Finally, participants also completed the Cultural Values Scale, rating 5 items on how power should be shared (Power Distance, eg, 'People in higher positions should make most decisions without consulting people in lower positions'; Cronbach's $\alpha=0.83) .{ }^{33}$ For each dimension, items were summed to form subscale scores.

\section{Data analysis}

For the primary analyses, survey responses were summarised with counts (\%) and medians (with IQR). To predict shifts in decision-making for family members relative to the self, we performed a classification tree analysis using recursive partitioning ('rpart'). ${ }^{34} 35$ This machine learning model allows multiple variables to be analysed simultaneously while accommodating complex relationships between predictors. ${ }^{36}$ For the model, input variables were the eight demographic variables, scores on both organ donation fear scales (for a family member and for the self), scores on the five culture-related scales (Vertical Collectivism, Horizontal Collectivism, Vertical Individualism, Horizontal Individualism and Power Distance) and overconfidence metrics for both family members and the self (whether organ donation discussions had been taken, confidence in decision-making and family awareness). To avoid overfitting, the final tree was obtained by requiring at least 10 participants per subgroup and a minimum Gini reduction of 0.01 within subgroups.

Finally, we reported two forms of inferential statistics: $\chi^{2}$ tests of independence (to examine the relation between various donation and overconfidence metrics) and Tukey's test (as a post-hoc test following recursive 


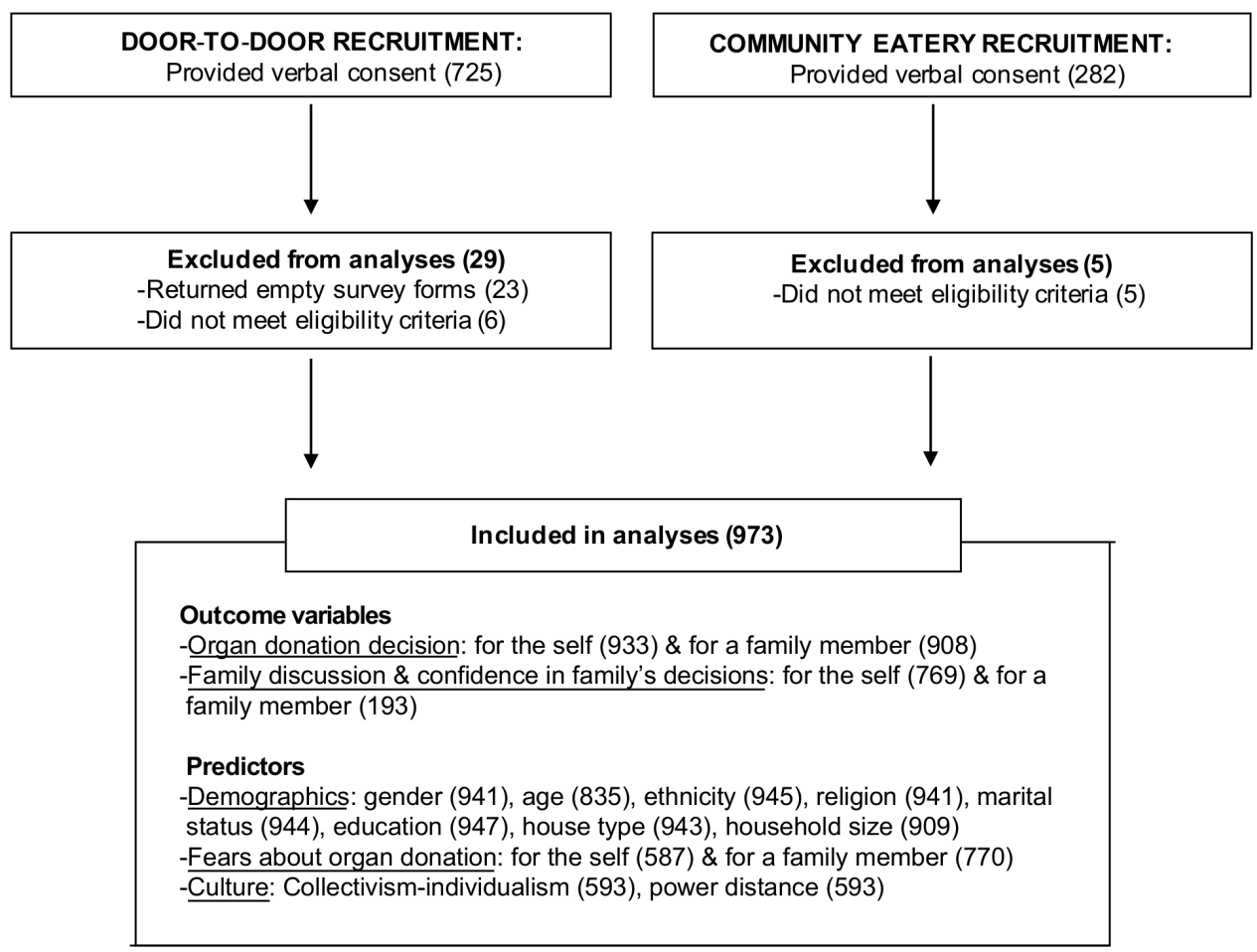

Figure 1 Flowchart of participant inclusion.

partitioning). For all statistical tests, Type 1 Decision Wise Error Rate was controlled at $\alpha=0.05$. All analyses were performed in SPSS V.25 and R 3.6.2.

\section{Patient and public involvement}

We did not involve patients or the public in the formulation of research questions or in data analysis. However, survey items were designed based on the authors' clinical experience discussing organ donation decisions with families.

\section{RESULTS}

\section{Description of the sample}

Participants were 973 adults from the general community (figure 1). As shown in table 1 , respondents were equally likely to have self-identified as male $(469(48.2 \%))$ or female $(472(48.5 \%)$ ), and had a mean age of 40.26 years (SD: 12.57 years). Respondents were comparable to Singapore's general population in gender, ethnicity, marital status and religion ( $\leq 5 \%$ difference). Notably, there was a greater representation from the $21-49$ age group $(64.8 \%$ vs $54.4 \%$ ), from residents of public housing $(89.7 \%$ vs $78.3 \%)$ and from recipients of tertiary education $(68.0 \%$ vs $48.2 \%) .{ }^{37}$ On the other hand, participants were less likely to be from one-to-two-member households than the general population $(16 \%$ vs $37 \%) .{ }^{37}$

\section{Deciding for the self versus a family member}

As shown in figure 2, one in five participants $(22.1 \%$, 95\% CI: $19.6 \%$ to $25.1 \%$ ) were willing to donate their own organs but were unwilling to donate a family member's organ. This corresponded to a drop-off in willingness to donate, with lower rates reported when deciding for family members than for themselves (95\% CI of difference: $11.7 \%$ to $20.9 \%) ; \chi^{2}(1)=48.29$, $\mathrm{p}<0.001)$.

\section{Predicting inconsistency in decision-making}

To understand inconsistency in decision-making, we used recursive partitioning to predict which of four possible categories participants belonged to: (1) individuals who were willing to donate both their own and their relatives' organs (hereafter referred to as 'consistent donors'), (2) individuals unwilling to donate either their own or their relatives' organs (hereafter referred to as 'consistent non-donors'), (3) individuals unwilling to donate their own organs but willing to donate a relative's (hereafter referred to as 'unwilling donors who agree'), or-importantly-(4) individuals willing to donate their own organs but not their relatives' (hereafter referred to as 'willing donors who refuse'). The final tree model identified participants' organ donation fears (self and family) and religion as the key predictors of category membership (figure 3).

As shown in figure 4, consistency was marked by more extreme values in organ donation fears. Consistent nondonors reported higher organ donation fears both for themselves and for family members ( $p$ values for Tukey post-hoc test: all $\leq 0.003$ for the self and all $\leq 0.008$ for family members), whereas consistent donors reported lower organ donation fears, relative to other groups ( $p$ values for Tukey post-hoc test: all <0.001). Consistent non-donors were also more likely to report a religious affiliation (Taoism or Chinese traditional beliefs, Islam, 
Table 1 Baseline characteristics of survey respondents

\begin{tabular}{|c|c|}
\hline Characteristics & $\mathbf{N}(\%)$ \\
\hline \multicolumn{2}{|l|}{ Gender } \\
\hline Male & $469(48.2)$ \\
\hline Female & $472(48.5)$ \\
\hline Did not answer & $32(3.3)$ \\
\hline \multicolumn{2}{|l|}{ Age group } \\
\hline $21-34$ & $316(32.8)$ \\
\hline $35-49$ & $311(32.0)$ \\
\hline $50-64$ & $171(17.2)$ \\
\hline $65+$ & $37(3.7)$ \\
\hline Did not answer & $138(14.2)$ \\
\hline \multicolumn{2}{|l|}{ Ethnicity } \\
\hline Chinese & 716 (73.6) \\
\hline Malay & $92(9.5)$ \\
\hline Indian & $86(8.8)$ \\
\hline Eurasian & $3(0.3)$ \\
\hline Others & $43(4.4)$ \\
\hline Did not answer & $33(3.4)$ \\
\hline \multicolumn{2}{|l|}{ Religion } \\
\hline Buddhism & $337(34.6)$ \\
\hline Taoism/traditional Chinese beliefs & $51(5.2)$ \\
\hline Islam & $112(11.5)$ \\
\hline Hinduism & $60(6.2)$ \\
\hline Sikhism & $2(0.2)$ \\
\hline Catholicism & $39(4.0)$ \\
\hline Christianity (Protestant) & $139(14.3)$ \\
\hline No religion & $189(19.4)$ \\
\hline Others & $12(1.2)$ \\
\hline Did not answer & $32(3.3)$ \\
\hline \multicolumn{2}{|l|}{ Education level } \\
\hline No formal education & $7(0.7)$ \\
\hline Primary school & $55(5.7)$ \\
\hline Secondary school/junior college & $223(22.9)$ \\
\hline $\begin{array}{l}\text { Tertiary (vocational training, polytechnic, } \\
\text { university) }\end{array}$ & $662(68.0)$ \\
\hline Did not answer & $26(2.7)$ \\
\hline \multicolumn{2}{|l|}{ Marital status } \\
\hline Single/dating & $343(35.3)$ \\
\hline Married & $554(56.9)$ \\
\hline Widowed/separated/divorced & $47(4.8)$ \\
\hline Did not answer & $29(3.0)$ \\
\hline \multicolumn{2}{|l|}{ House type } \\
\hline Public housing: $1-2$ room flat/rental unit & $20(2.1)$ \\
\hline Public housing: 3-room flat & $303(31.1)$ \\
\hline Public housing: 4-room flat & $303(31.1)$ \\
\hline Public housing: 5-room or executive flats & $247(25.4)$ \\
\hline
\end{tabular}

Continued
Table 1 Continued

\begin{tabular}{|ll|}
\hline Characteristics & $\mathbf{N}(\%)$ \\
\hline Condominium and/or private apartments & $41(4.2)$ \\
\hline Landed property & $28(2.9)$ \\
\hline Others & $1(0.1)$ \\
\hline Did not answer & $30(3.1)$ \\
\hline Household size & \\
\hline 1 & $30(3.1)$ \\
\hline 2 & $126(12.9)$ \\
\hline 3 & $221(22.7)$ \\
\hline 4 & $254(26.1)$ \\
\hline 5 & $175(18.0)$ \\
\hline 6 & $61(6.3)$ \\
\hline $7+$ & $42(4.3)$ \\
\hline Did not answer & $64(6.6)$ \\
\hline
\end{tabular}

Hinduism or Catholicism), whereas consistent donors were more likely to have no religion.

In contrast, predicting willing donors who refused family donation was not as straightforward. This group was identified as those who met a series of criteria: (1) having low organ donation fears for themselves (scores of $<2.6$ out of 5 ) but greater fears for family members (between 2.8 and 3.8 out of 5); (2) having Buddhist or Christian beliefs; and (3) not holding extreme views about how power should be shared in society (power distance scores $\geq 5.5$ ). Notably, none of the criteria uniquely identified this group. For example, when paired with other criteria, Buddhism and Christianity were also associated with consistent non-donors and donors.

\section{Overconfidence in family decision-making}

Following the surrogacy literature ${ }^{23}$ we examined whether overconfidence characterized family decision-makingthat is, whether participants reported high confidence that they would carry out their relatives' organ donation wishes despite not knowing what these wishes were. As shown in figure 5, nearly four in five participants $(78 \%$, 95\% CI: $72.1 \%$ to $83.9 \%$ ) had never discussed organ donation with a close family member they could be tasked to make decisions for. Correspondingly, only one in three participants (29.9\%, 95\% CI: $23.4 \%$ to $36.4 \%$ ) were aware of their relative's organ donation wishes. We note, however, that higher rates of awareness were reported among those who had engaged in prior discussion $(80 \%$, 95\% CI: $67.6 \%$ to $92.4 \%)$ than those who had not $(22.2 \%$, $95 \%$ CI: $15.4 \%$ to $29.0 \%) ; \chi^{2}(4, \mathrm{n}=184)=55.58, \mathrm{p}<0.001$.

Although few participants were aware of family members' wishes, participants were nonetheless very confident that they would respect these wishes on their relatives' deaths. When asked to rate how confident they were (using a 5-point scale), the median rating was 5-'absolutely confident' (IQR: 3-5). Further, confidence was high both among those who had previously discussed 


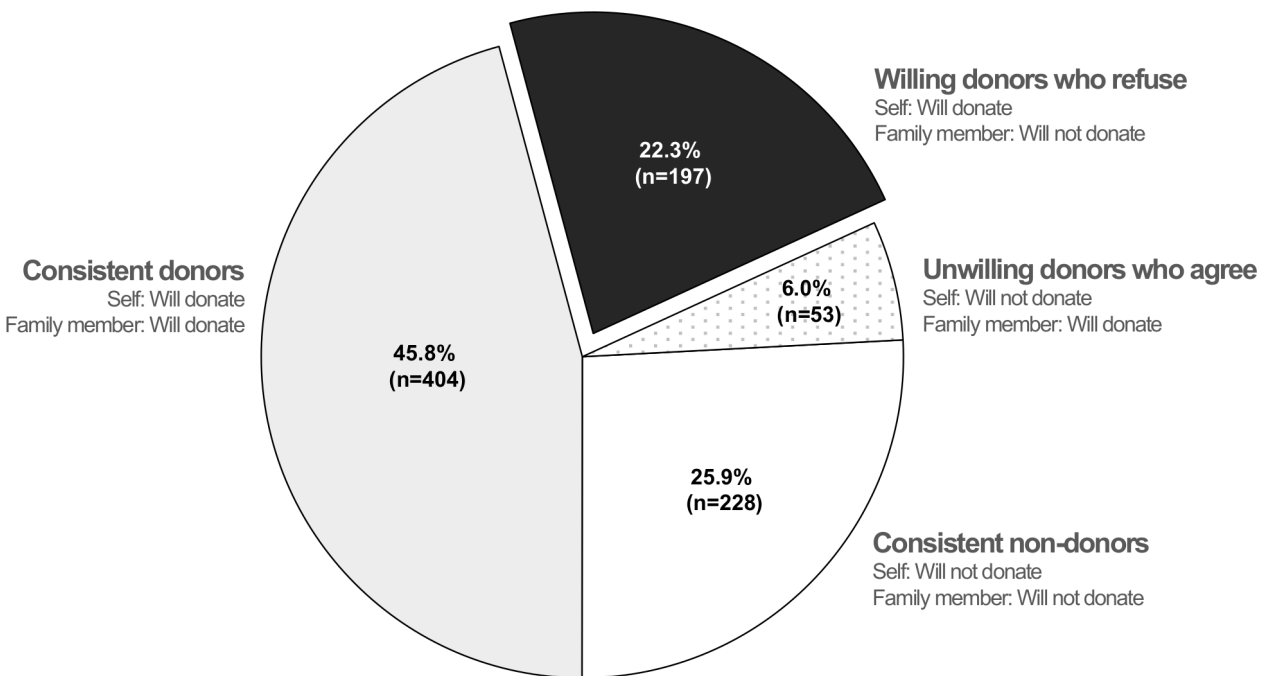

Figure 2 The distribution of participants as a function of their willingness to donate their own organs and donate a family member's organs.

donation with their relatives $(89.7 \%$ gave a rating of 4 or 5; $95 \%$ CI: $80.2 \%$ to $99.2 \%$ ), and among those who had not $(67.1 \%, 95 \%$ CI: $59.4 \%$ to $74.8 \%)$; confidence did not differ significantly as a function of whether participants had engaged in prior discussion $\left(\chi^{2}(4, \mathrm{n}=182)=8.44\right.$, $\mathrm{p}=0.08)$.

As a comparison, we examined the corresponding questions pertaining to participants' own wishes on organ donation (figure 5). The results were near-identical: four in five participants $(79.1 \%$, $95 \%$ CI: $76.1 \%$ to $82.1 \%$ ) had never discussed their wishes with their family, and only one in three (29.9\%, $95 \%$ CI: $26.7 \%$ to $33.1 \%)$ perceived that their family was aware of their wishes. Nonetheless, the majority of participants felt confident that their family would carry out their wishes on death $(64.0 \%$ gave a rating of 4 or $5 ; 95 \%$ CI: $60.6 \%$ to $67.4 \%$ ).

Finally, we ran exploratory analyses comparing this set of metrics among participants of the four decision categories previously identified (consistent non-donors, consistent donors, unwilling donors willing to donate relatives' organs and willing donors who refuse family donation). As shown in figure 6, donation decisions related to

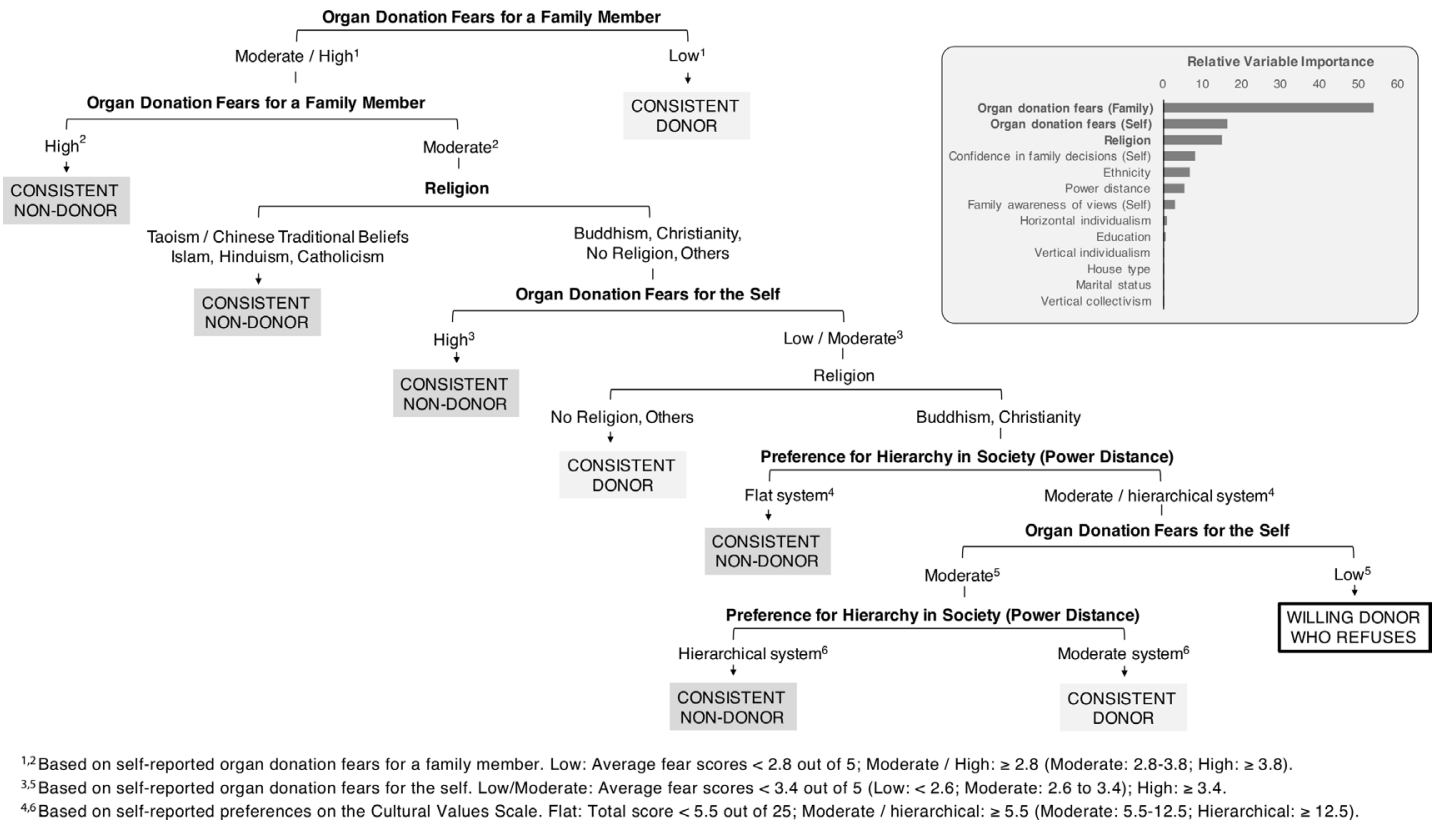

Figure 3 A machine learning technique-recursive partitioning-was used to predict which of four categories the participants belonged to: (1) consistent donors (willing to donate for both the self and for a relative); (2) consistent non-donors (unwilling to donate in both cases); (3) willing donors who refuse (being willing to donate for themselves but not for next-of-kin); or (4) unwilling donors who agree (being unwilling for the self but willing for next-of-kin). The final model, presented as a flow chart, shows how participant information was used to maximize information gain at each level of the chart, a factor was chosen that allowed the most number of participants to be categorized. As shown in the bar graph, participants' organ donation fears and religion emerged as the key predictors (model classification accuracy: 52\%, above the chance level of $25 \%$ ). 

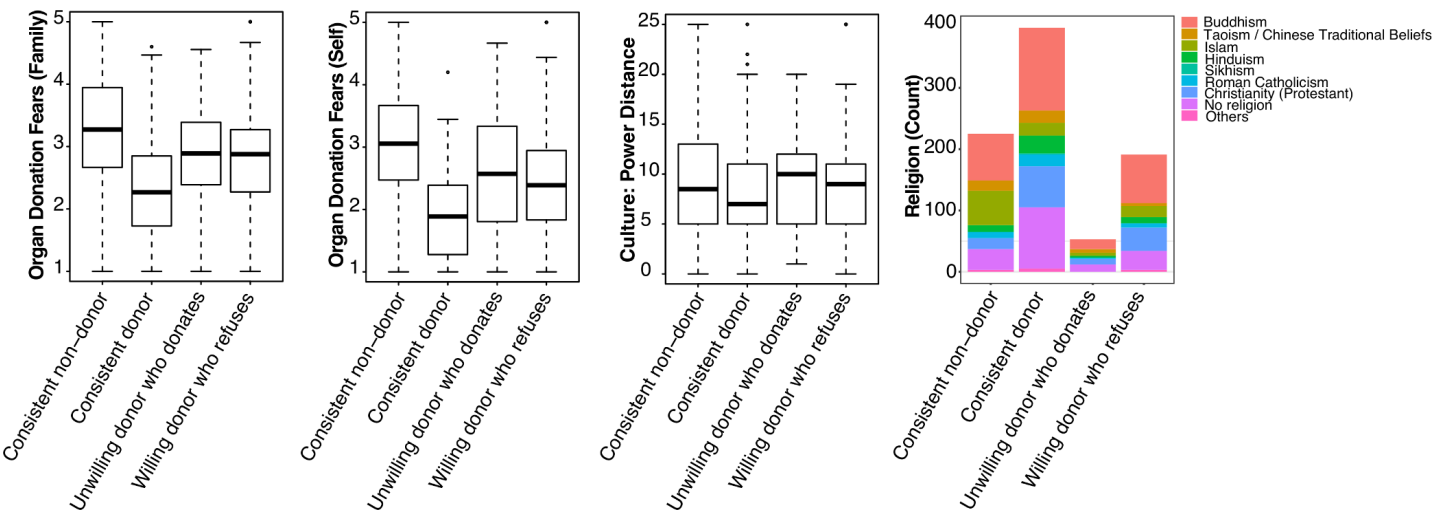

Figure 4 Participants' organ donation fear scores (for a family member and for themselves), power distance scores, and religion as a function of their donation decisions.

participants' awareness of their relatives' wishes, $\chi^{2}(3$, $\mathrm{n}=182)=9.01, \mathrm{p}=0.03$. Namely, consistent non-donors were more likely to report awareness than consistent donors $(\chi 2(1, \mathrm{n}=147)=5.81, \mathrm{p}=0.02)$, unwilling donors who donate relatives' organs $\left(\chi^{2}(1, n=25)=3.95, \mathrm{p}=0.047\right)$ or willing donors who refuse family donation $\left(\chi^{2}(1\right.$, $\mathrm{n}=48)=7.31, \mathrm{p}=0.007)$; whereas awareness did not differ significantly among participants in the latter three categories (smallest $\mathrm{p}=0.29$ ). Finally, we found no evidence that either prior discussion or confidence differed as a function of decision categories (smallest $\mathrm{p}=0.49$ ).

\section{DISCUSSION}

Increasingly, social science research underscores how the decision-making process differs when one decides for another person as compared with himself or herself. ${ }^{38} 39$ Through our research, we applied this framework to organ donation in a novel manner, seeking to understand family refusal by accounting for the decision-maker's mindset (vis-à-vis deciding for the self).

First, analogous to healthcare surrogacy, we observed for the first time how individuals were overconfident in making donation decisions for close family members. Although they had not discussed their family members' wishes nor were aware of these, participants were nonetheless confident that they could carry out their relatives' wishes on death. Likewise, when individuals considered decisions made on their behalf, they expressed confidence that family members would do their bidding-despite not having made their wishes known previously. In both cases, being assured of the family decision-making process far exceeded the basis for doing so.

Our findings of overconfidence provide a baseline for campaigns that urge individuals to discuss organ donation with their families. ${ }^{40}$ Although it is widely recognised that discussion increases family consent, promoting

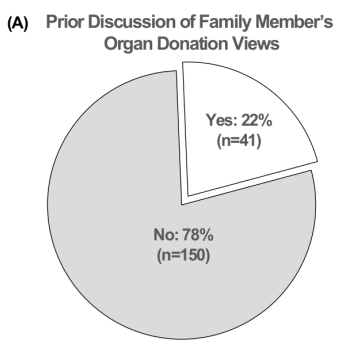

(B)

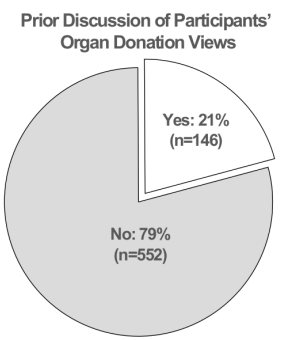

Awareness of Family Member's Views

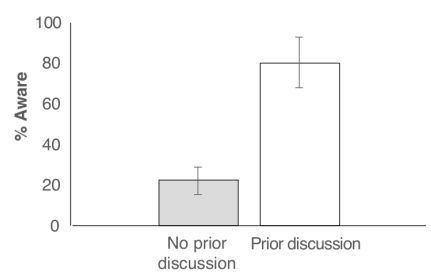

Family Awareness of Participants' Views

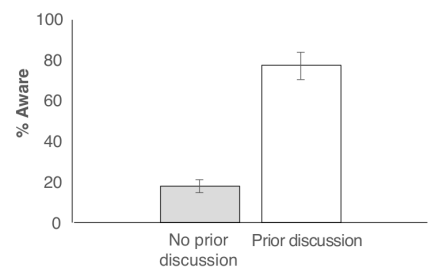

Confidence in Respecting Family Member's Views Upon Death

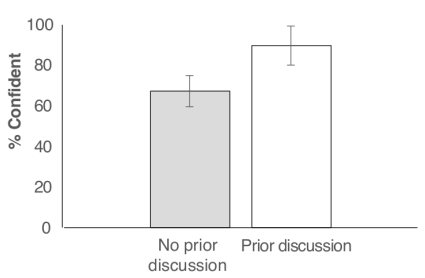

Confidence of Family Respecting Participants Views Upon Death

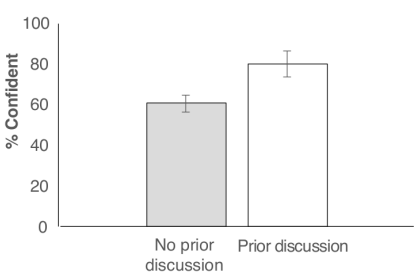

Figure 5 (A) Participants reported whether they had discussed organ donation with a close family member they may be tasked to make decisions for (left panel). The bar graphs depict the per cent of participants in each category (no prior discussion vs prior discussion) who reported being aware of their family members' views (middle panel), and confident that they would respect their family members' wishes on death (right panel). (B) Similarly, participants reported whether they had discussed their own views with their family (left panel), whether their family was aware (middle panel) and how confident they were that their family would carry out their wishes (right panel). Vertical lines represent $95 \%$ Cls. 

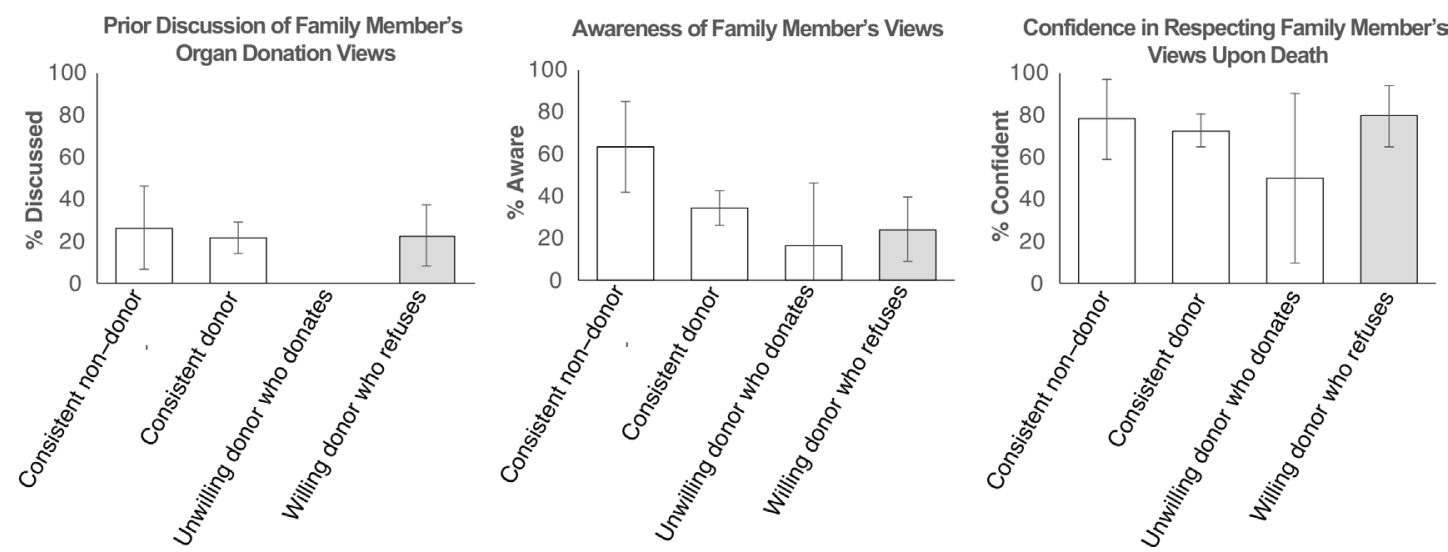

Figure 6 Bar graphs depict the per cent of participants in each category (consistent non-donors, consistent donors, unwilling donors who donate relatives' organs or willing donors who refuse family donations) who had discussed organ donation with a close family member (left panel), were aware of their relative's wishes (middle panel) and were confident of carrying these wishes out (right panel). Vertical lines represent 95\% Cls.

discussion can be challenging, and studies have sought to identify persons most willing to take this step. ${ }^{41-43}$ Beyond person-based characteristics, however, it seems likely that overconfident individuals may find it redundant to initiate discussion, whether to make their wishes known or to find out about their relatives' wishes. If this account is true, donation campaigns could benefit from addressing overconfidence as a precursor to stimulating family discussion.

In line with previous findings, we further documented a systematic shift when participants made decisions for family members. ${ }^{1819}$ Namely, participants were less willing to donate their relatives' organs than their own, with one in five switching from being willing donors themselves to refusing donation for their relatives. Extending prior research, we also identified for the first time two key factors-fears about organ donation and religion-that predicted when decisions for the family matched decisions for the self.

Examining the two key factors more closely, we found that consistent donors and non-donors were identified by strong influences-having extreme levels of organ donation fears (eg, low fears predicting consistent donation), or strong religious views (eg, affiliations with Taoism, Islam, Hinduism and Catholicism predicting refusal). While each factor had previously been linked to individual and family decision-making independently ${ }^{1844} 45$ and to the broader acceptance of organ donation within a society, ${ }^{46}$ our findings additionally highlight the role of these factors in decision consistency-making the same organ donation choice for both the self and for a family member. By contrast, the majority of those who switched-namely, willing donors who refused family donation-were less driven by these factors. Instead of relying on strong principles, this group may have relied on heuristics-rule of thumb guidelines that simplify decision-making. ${ }^{47}$ Thus, being unaware of their relatives' wishes but overconfident in their decision-making abilities, they may have reverted to the conservative decision of refusing organ donation.
If our account of family refusal is true, then decisionmaking research would suggest that refusal may be minimized if decision-makers can be nudged to avoid heuristics. ${ }^{47}$ Since family refusal rates exceed those of individuals, moving closer to individuals' actual wishes is likely to increase the supply of transplantable organs. To this end, donation programs may benefit from focusing on decision-makers willing to donate their own organs, urging them to: (1) become aware of their relatives' wishes (prior to his/her death); or (2) undergo a more thorough decision-making process to work out their relatives' wishes (instead of simply relying on the conservative heuristic to abstain from organ donation).

\section{Limitations}

We note several limitations of our study. First, to compare decisions for the self versus a family member, we relied on hypothetical willingness to donate. This survey methodology—while commonly used—stands in contrast to retrospective audits of hospital records where actual donation decisions are examined. ${ }^{6}$ Future research will need to determine whether our findings generalize to real-life contexts where-for example-decisions have to be made while standing at the hospital bed of a family member. In a similar vein, the self-reported nature of our study predictors (eg, whether participants had discussed organ donation, organ donation fears) may have been influenced by recall biases. Finally, although our sample was representative of the general population, all data were collected in an urban setting and may not apply to rural contexts.

\section{Conclusions}

In summary, we conducted an in-depth analysis of psychological processes that may underlie family refusal. Our findings underscore how decision-making differs when one considers a family member rather than the self. Consequently, addressing the decision-maker's mindset (eg, overconfidence, the use of heuristics) may increase actualization rates amidst a worldwide organ shortage. 
Author affiliations

${ }^{1}$ Department of Pain Medicine, Singapore General Hospital, Singapore

${ }^{2}$ Anaesthesiology Academic Clinical Program, Duke-NUS Medical School, Singapore

${ }^{3}$ Yong Loo Lin School of Medicine, National University of Singapore, Singapore

${ }^{4}$ Department of Anesthesiology, Singapore General Hospital, Singapore

${ }^{5}$ Division of Social Sciences, Yale-NUS College, Singapore

${ }^{6}$ Department of Surgical Intensive Care, Singapore General Hospital, Singapore

${ }^{7}$ Neuroscience and Behavioral Disorders Programme, Duke-NUS Medical School, Singapore

\section{Twitter Jean C J Liu @jeancjliu}

Acknowledgements The authors gratefully acknowledge Madhumitha Ayyappan, Rayner Ng, Joanna Chue, Keith Tong, Joel Chew, Chow Kit Ying, Sean Nicholas, Hans Toby Limanto, Sophie Ang, Dinh Hai Bao Lien, Claris Nghai, Pei Jia Ying and Nasir Ruslan for their assistance in the preparation of surveys, data collection and data entry.

Contributors CWL, LNC, AA and JCJL participated in research design, data analysis and the writing of the paper. BLZ, CKYL and WHN participated in research design and performance of the research. TS and VKH participated in research design and the writing of the paper. JCJL was responsible for the overall content of the paper.

Funding This work was supported by a grant awarded to CWL, TS, VKH, and JCJL from the National University of Singapore Humanities and Social Sciences research fund (grant number: HSS-1502-P02).

Competing interests None declared.

Patient consent for publication Not applicable.

Ethics approval Ethical approval was obtained from the National University of Singapore's Institutional Review Board approved all procedures (IRB A-16-131), the study protocol was registered on ClinicalTrials.gov (NCT04303624), and participants gave verbal consent.

Provenance and peer review Not commissioned; externally peer reviewed.

Data availability statement Data are available upon reasonable request. Data are available upon request (subject to approval from the relevant ethics boards).

Supplemental material This content has been supplied by the author(s). It has not been vetted by BMJ Publishing Group Limited (BMJ) and may not have been peer-reviewed. Any opinions or recommendations discussed are solely those of the author(s) and are not endorsed by BMJ. BMJ disclaims all liability and responsibility arising from any reliance placed on the content. Where the content includes any translated material, BMJ does not warrant the accuracy and reliability of the translations (including but not limited to local regulations, clinical guidelines, terminology, drug names and drug dosages), and is not responsible for any error and/or omissions arising from translation and adaptation or otherwise.

Open access This is an open access article distributed in accordance with the Creative Commons Attribution Non Commercial (CC BY-NC 4.0) license, which permits others to distribute, remix, adapt, build upon this work non-commercially, and license their derivative works on different terms, provided the original work is properly cited, appropriate credit is given, any changes made indicated, and the use is non-commercial. See: http://creativecommons.org/licenses/by-nc/4.0/.

\section{ORCID iDs}

Christopher Weiyang Liu http://orcid.org/0000-0001-7807-9263

Jean C J Liu http://orcid.org/0000-0003-0137-3450

\section{REFERENCES}

1 World Health Organization. Human organ transplantation, 2020. Available: https://www.who.int/transplantation/organ/en/ [Accessed 24 Jul 2020].

2 WHO-ONT. Global Observatory on donation and transplantation (GODT) data, 2017. Available: http://www.transplant-observatory.org/ [Accessed 27 Nov 2019].

3 The Lancet Gastroenterology Hepatology. Increasing organ donation rates: is legislation enough? Lancet Gastroenterol Hepatol $2017 ; 2: 235$.

4 Scheuher C. What is being done to increase organ donation? Crit Care Nurs Q 2016;39:304-7.

5 Barber K, Falvey S, Hamilton C, et al. Potential for organ donation in the United Kingdom: audit of intensive care records. BMJ 2006;332:1124-7.
6 Cignarella A, Redley B, Bucknall T. Organ donation within the intensive care unit: a retrospective audit. Aust Crit Care 2020;33:167-74.

7 Hulme W, Allen J, Manara AR, et al. Factors influencing the family consent rate for organ donation in the UK. Anaesthesia 2016;71:1053-63.

8 Simpkin AL, Robertson LC, Barber VS, et al. Modifiable factors influencing relatives' decision to offer organ donation: systematic review. BMJ 2009;338:b991-1063.

9 Walker W, Broderick A, Sque M. Factors influencing bereaved families' decisions about organ donation: an integrative literature review. West J Nurs Res 2013;35:1339-59.

10 Mojtabaee M, Ghorbani F, Mohsenzadeh M, et al. Update on causes of family refusal for organ donation and the related factors: reporting the changes over 6 years. Transplant Proc 2018;50:10-13.

11 Siminoff LA, Gordon N, Hewlett J, et al. Factors influencing families' consent for donation of solid organs for transplantation. JAMA 2001;286:71-7.

12 Michetti CP, Newcomb A, Thota V, et al. Organ donation education in the ICU setting: a qualitative and quantitative analysis of family preferences. J Crit Care 2018;48:135-9.

13 Siminoff LA, Lawrence $\mathrm{RH}$. Knowing patients' preferences about organ donation: does it make a difference? J Trauma 2002;53:754-60.

14 Liu CW, Yeo C, Lu Zhao B, et al. Brain death in Asia: do public views still influence organ donation in the 21 st century? Transplantation 2019;103:755-63.

15 Wakefield CE, Watts KJ, Homewood J, et al. Attitudes toward organ donation and donor behavior: a review of the International literature. Prog Transplant 2010;20:380-91.

16 May T, Aulisio MP, DeVita MA. Patients, families, and organ donation: who should decide? Milbank Q 2000;78:323-36.

17 US Department of Health and Human Services. 2012 national survey of organ donation attitudes and behaviors, 2013. Available: https:// www.organdonor.gov/sites/default/files/ about-dot/files/nationalsurv eyorgandonation.pdf [Accessed 27 Nov 2019].

18 Sanner M. A comparison of public attitudes toward autopsy, organ donation, and anatomic dissection. A Swedish survey. JAMA 1994;271:284-8.

19 Mossialos E, Costa-Font J, Rudisill C. Does organ donation legislation affect individuals' willingness to donate their own or their relative's organs? Evidence from European Union survey data. BMC Health Serv Res 2008;8:48.

20 Polman E, Wu K. Decision making for others involving risk: a review and meta-analysis. J Econ Psychol 2020;77:102184.

21 Wendler $\mathrm{D}$. The theory and practice of surrogate decision-making. Hastings Cent Rep 2017;47:29-31.

22 Shalowitz DI, Garrett-Mayer E, Wendler D. The accuracy of surrogate decision makers. Arch Intern Med 2006;166:493-7.

23 Fried TR, Zenoni M, lannone L, et al. Assessment of surrogates' knowledge of patients' treatment goals and confidence in their ability to make surrogate treatment decisions. JAMA Intern Med 2019;179:267-8.

24 Fried TR, Bullock K, lannone L, et al. Understanding advance care planning as a process of health behavior change. J Am Geriatr Soc 2009;57:1547-55.

25 Wendler D, Rid A. Systematic review: the effect on surrogates of making treatment decisions for others. Ann Intern Med 2011;154:336-46.

26 Bramstedt KA. Family refusals of registered consents: the disruption of organ donation by double-standard surrogate decision-making. Intern Med J 2013;43:120-3.

27 IRODaT. International registry in organ donation and transplantation. Barcelona, Spain: IRODaT - DTI Foundation, 2021.

28 The Law Revision Commission. Human organ transplant act (Chapter 131A). Singapore statutes online website, 2012. Available: https:// sso.agc.gov.sg/Act/HOTA1987 [Accessed 16 May 2018].

29 Singapore Ministry of Health. The medical (therapy, education and research) act (MTERA). Available: https://www.moh.gov.sg/policiesand-legislation/the-medical-(therapy-education-and-research)-act-( mtera) [Accessed 24 Jul 2020].

30 Kwek TK, Lew TWK, Tan HL, et al. The transplantable organ shortage in Singapore: has implementation of presumed consent to organ donation made a difference? Ann Acad Med Singap 2009;38:346-53.

31 Passmore C, Dobbie AE, Parchman M, et al. Guidelines for constructing a survey. Fam Med 2002;34:281-6.

32 Triandis HC, Gelfand MJ. Converging measurement of horizontal and vertical individualism and collectivism. J Pers Soc Psychol 1998;74:118-28. 
33 Yoo B, Donthu N, Lenartowicz T. Measuring Hofstede's five dimensions of cultural values at the individual level: Development and validation of CVSCALE. J Int Consum Mark 2011;23:193-210.

34 Therneau TM, Atkinson EJ, Foundation M. An introduction to recursive partitioning using the RPART routines. CRAN: Mayo Foundation, 2018.

35 Venkatasubramaniam A, Wolfson J, Mitchell N, et al. Decision trees in epidemiological research. Emerg Themes Epidemiol 2017;14:11.

36 Breiman L, Friedman J, Stone CJ. Classification and regression trees. Boca Raton, Florida: Taylor and Francis, 1984

37 Singapore Department of Statistics. Latest data. Singstat website, 2020. Available: https://www.singstat.gov.sg/whats-new/latest-data [Accessed 28 May 2020].

38 Tunney RJ, Ziegler FV. Toward a psychology of surrogate decision making. Perspect Psychol Sci 2015;10:880-5.

39 Polman E. Self-other decision making and loss aversion. Organ Behav Hum Decis Process 2012;119:141-50.

40 NHS Blood and Transplant. How to discuss your decision. Yes I donate organ donation website. Available: https://www. organdonation.nhs.uk/tell-your-family-and-friends/how-to-discussyour-decision/ [Accessed 14 Mar 2020].
41 Newton JD, Burney S, Hay M, et al. A profile of Australian adults who have discussed their posthumous organ donation wishes with family members. J Health Commun 2010;15:470-86.

42 Smith SW, Lindsey LLM, Kopfman JE, et al. Predictors of engaging in family discussion about organ donation and getting organ donor cards witnessed. Health Commun 2008;23:142-52.

43 Smith SW, Kopfman JE, Lindsey LLM, et al. Encouraging family discussion on the decision to donate organs: the role of the willingness to communicate scale. Health Commun 2004;16:333-46.

44 Merz E-M, van den Hurk K, de Kort WLAM. Organ donation registration and decision-making among current blood donors in the Netherlands. Prog Transplant 2017;27:266-72.

45 Carmack HJ, DeGroot JM. Communication apprehension about death, religious group affiliation, and religiosity: predictors of organ and body donation decisions. Omega 2020;81:627-47.

46 Riambau G, Lai C, Zhao BL, et al. Legal origins, religion and health outcomes: a cross-country comparison of organ donation laws. $J$ Institutional Econ 2021;17:217-26.

47 Kahneman D. Thinking, fast and slow. London, United Kingdom: Penguin Books Ltd, 2011. 